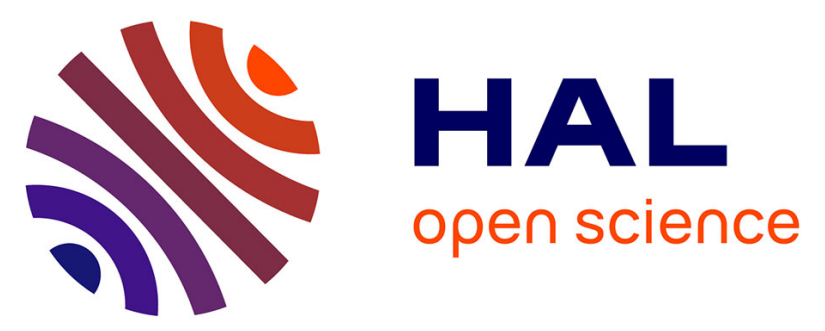

\title{
Genome-wide association study identifies TF as a significant modifier gene of iron metabolism in HFE hemochromatosis
}

\author{
Marie de Tayrac, Marie-Paule Roth, Anne-Marie Jouanolle, Hélène Coppin,
} Gérald Le Gac, Alberto Piperno, Claude Férec, Sara Pelucchi, Virginie Scotet, Edouard Bardou-Jacquet, et al.

\section{To cite this version:}

Marie de Tayrac, Marie-Paule Roth, Anne-Marie Jouanolle, Hélène Coppin, Gérald Le Gac, et al.. Genome-wide association study identifies TF as a significant modifier gene of iron metabolism in HFE hemochromatosis. Journal of Hepatology, 2015, 62 (3), pp.664-672. 10.1016/j.jhep.2014.10.017 . hal01091987

\section{HAL Id: hal-01091987}

\section{https://hal-univ-rennes1.archives-ouvertes.fr/hal-01091987}

Submitted on 8 Dec 2014

HAL is a multi-disciplinary open access archive for the deposit and dissemination of scientific research documents, whether they are published or not. The documents may come from teaching and research institutions in France or abroad, or from public or private research centers.
L'archive ouverte pluridisciplinaire HAL, est destinée au dépôt et à la diffusion de documents scientifiques de niveau recherche, publiés ou non, émanant des établissements d'enseignement et de recherche français ou étrangers, des laboratoires publics ou privés. 
Genome-wide association study identifies TF as a significant modifier gene of iron metabolism in HFE hemochromatosis

\section{Short Title - GWAS of HFE hemochromatosis}

Marie de Tayrac ${ }^{1,2,3}$, Marie-Paule Roth ${ }^{4,5,6}$, Anne-Marie Jouanolle ${ }^{3}$, Hélène Coppin $^{4,5,6}$, Gérald le Gac ${ }^{7,8}$, Alberto Piperno ${ }^{9}$, Claude Férec ${ }^{7,8}$, Sara Pelucchi ${ }^{9}$, Virginie Scotet ${ }^{7,8}$, Edouard Bardou-Jacquet ${ }^{10,11}$, Martine Ropert ${ }^{12}$, Régis Bouvet ${ }^{3,13}$, Emmanuelle Génin ${ }^{7}$, Jean Mosser ${ }^{1,2,3 *}$, Yves Deugnier ${ }^{10,11,14 *}$

* Equally contributing contributors

1- CNRS, UMR 6290, Institut Génétique et Développement de Rennes, F-35043 Rennes, France

2- Université de Rennes 1, UEB, Biosit, Faculté de Médecine, F-35043 Rennes, France

3- CHU Rennes, Service de Génétique Moléculaire et Génomique, F-35033 Rennes, France

4- Inserm, U1043, F31024 Toulouse, France

5- CNRS, U5282, F31024 Toulouse, France

6- Université de Toulouse, UPS, Centre de Physiopathologie de Toulouse Purpan (CPTP), F31062 Toulouse, France

7- Inserm UMR1078, Université de Brest, SFR SclnBioS, CHRU, F-29200 Brest, France

8- Etablissement Français du Sang - Bretagne, Laboratoire de Génétique Moléculaire et d'Histocompatibilité, F-29200 Brest, France

9- University of Milano-Bicocca, Department of Health Sciences, Centre for Iron Disorders, S. Gerardo Hospital, Monza, Italy

10- CHU de Rennes, Liver Unit and French Reference Centre for Rare Iron Overload Diseases of Genetic Origin, F-35033 Rennes, France

11- INSERM, UMR 991, Equipe Fer et Foie, F-35033 Rennes, France

12- CHU Rennes, Service de Biochimie, F-35033 Rennes, France

13- Plate-forme Génomique Santé Biogenouest, Biosit, F-35043 Rennes, France 14- INSERM, Centre of Clinical Investigation 0203, CHU de Rennes, F-35033 Rennes cedex 


\section{Correspondence}

Marie de Tayrac

CNRS UMR6290 Institut de Génétique et Développement de Rennes

Service de Génétique Moléculaire et Génomique

2, avenue Henri Le Guilloux

35033 Rennes cedex 9

France

Marie.detayrac@univ-rennes1.fr

Tel: +33 (0)2 99289970

Fax: +33 (0)2 99289248

Word count: $\mathbf{4 1 2 3}$

\section{Number of Figures: 2}

\section{Number of tables: 2}

\section{List of abbreviations}

$\mathrm{HH}$ : Hereditary hemochromatosis

GWAS: genome-wide association study

SNP: Single Nucleotide Polymorphism

HAS: Haute Autorité de santé

\section{Conflict of interest: None}

\section{Financial Support}

The study was granted by the Programme Hospitalier de Recherche Clinique (PHRC

National 2008), the Agence Nationale de la Recherche (ANR-08-GENO-034), and the Fonds d'Aide à la Recherche (FAR) en Hépato-Gastroentérologie de la Société Nationale Française de Gastro-Entérologie (2011). It was also supported by the Association Fer et Foie.

\section{Author's Contributions}


Y.D. and J.M., along with M-PR. and E.G. conceived the study, obtained financial support and were responsible for study design. M.D.T and E.G. performed all statistical analyses and were responsible for data interpretation, with contributions of Y.D.. R.B., M-PR. and H.C. were responsible for sample processing and performed whole-genome and custom genotyping experiments. A-M.J., G.L.G, A.P., C.F., S.P., V.S., E.B-J, M.P., M-PR., and Y.D. coordinated the recruitment of subjects and the collection of phenotypic data. M.D.T drafted the initial manuscript, and M.R., G.L.G., A.P., J.M., E.G. and Y.D. provided critical revision for important intellectual content. All authors critically reviewed the manuscript revisions and approved the final manuscript. 


\section{Abstract}

Background. Hereditary hemochromatosis $(\mathrm{HH})$ is the most common form of genetic iron loading disease. It is mainly related to the HFE C282Y/C282Y homozygous genotype that is however a necessary but not a sufficient condition to develop clinical and even biochemical $\mathrm{HH}$. This suggests that modifiers genes are likely involved in the expressivity of the disease. Our aim was to identify such modifier genes.

Patients and methods. We performed a genome-wide association study (GWAS) using DNAs collected from 474 unrelated C282Y homozygotes. Associations were examined for both quantitative iron burden indices and clinical outcomes with 534,213 single nucleotide polymorphisms (SNP) genotypes, with replication analyses in an independent sample of $748 \mathrm{C} 282 \mathrm{Y}$ homozygotes from four different European centres.

Results. One SNP met genome-wide statistical significance for association with transferrin concentration (rs3811647, GWAS p-value of $7 \times 10^{-9}$ and replication pvalue of $5 \times 10^{-13}$ ). This SNP located within intron 11 of TF gene had pleiotropic effect on serum iron (GWAS p-value of $4.9 \times 10^{-6}$ and replication p-value of $3.2 \times 10^{-6}$ ). Both serum transferrin and iron levels were associated with serum ferritin levels, amount of iron removed and global clinical stage $(p<0.01)$. Serum iron levels were also associated with fibrosis stage $(\mathrm{p}<0.0001)$.

Conclusion. This GWAS, the largest one performed so far in unselected HFE-HH patients, identified the rs3811647 polymorphism in the TF gene as the only SNP significantly associated with iron metabolism through serum transferrin and iron levels. Because these two outcomes were clearly associated with the biochemical and clinical expression of the disease, an indirect link between the rs3811647 polymorphism and the phenotypic presentation of HFE-HH is likely.

\section{Keywords}

HFE-hemochromatosis, GWAS, transferrin 


\section{Introduction}

Genetic hemochromatoses are hereditary disorders proceeding from impairment in the production and/or activity of the key regulator of plasma iron, hepcidin, and resulting in progressive iron loading of parenchymas. HFE-hemochromatosis accounts for more than $95 \%$ of genetic hemochromatosis cases in Caucasian populations [1]. It is chiefly related to one major mutation, p.Cys282Tyr (C282Y), whose frequency ranges from $5 \%$ to $15 \%$ according to an increasing gradient from South/East to North/West but whose penetrance is far from complete [2].

Large studies based on systematic genotyping of large populations [2-6] have consistently found that transferrin saturation and serum ferritin levels, the key biochemical markers of genetic hemochromatosis, were significantly increased in C282Y homozygotes when compared to sex-matched controls with other HFE genotypes. According to studies, the percentage of C282Y homozygous subjects with elevated transferrin saturation ranged from 73 to $84 \%$ in males compared to 40 to $73 \%$ in females. The same was found for serum ferritin levels with a prevalence of increased values ranging from 70 to $88 \%$ in males and 33 to $69 \%$ in females. As a whole, the biochemical penetrance of $\mathrm{C} 282 \mathrm{Y}$ in homozygotes can be estimated as about $75 \%$ in males and $50 \%$ in females. However, only a few studies of the clinical expressivity of C282Y homozygotes achieved a sufficient statistical power and referred to a control group to allow for a correct interpretation of the data. [2,5,7-9] Based on these studies, it can be concluded that the clinical expressivity of the C282Y homozygous genotype is indisputably much lower than previously admitted, averaging $28 \%$ in males and $1 \%$ in females when using strict definitions of both iron overload and iron-related organ damage [2]. The main manifestations of HFEhemochromatosis are chronic fatigue, arthritis and liver disease. The frequency of heart disease and diabetes are not significantly increased in C282Y homozygotes compared with controls [1]. However fatigue and arthritis are not clearly correlated with the amount of iron burden. With respect to liver disease, serum ferritin levels lower than $1000 \mu \mathrm{g} / \mathrm{L}$ allow exclusion of significant fibrosis, as demonstrated by Guyader et al [10] and confirmed by Allen et al [2]. Thus C282Y homozygosity appears to be a necessary but not a sufficient condition for the development of HFE- 
hemochromatosis and the existence of both environmental and genetic modifiers of its penetrance is strongly suggested.

Although familial studies have shown that non-HFE iron-related genes are involved in the modulation of iron burden in C282Y homozygotes, only a few putative genetic modifiers have been identified so far in humans. A mitochondrial polymorphism has been reported as more frequent in iron loading expressing than in non-expressing C282Y homozygotes [11] but this was not confirmed by another study [12]. Coinheritance of mutations in the hepcidin gene (HAMP) $[13,14]$ or in the hemojuvelin gene (HFE2) [15] together with C282Y homozygosity was found to be associated with more severe iron burden of earlier onset in a French cohort of C282Y homozygotes $[13,15]$. However these mutations have a frequency lower than $2 \%$ among C282Y homozygotes and can thus explain increased disease severity in a few patients only. Based on these results, the BMP - SMAD pathway regulating hepcidin production was highlighted as an important pathway that was likely including potential modifying genes. This was confirmed by the finding, in a large cohort of C282Y homozygotes, of an association between common variants in the BMP pathway and the level of iron burden $[16,17]$. The full expression of HFE-hemochromatosis may thus be linked to abnormal hepatic expression of hepcidin, through both impairment in HFE function and functional modulation in the BMP pathway. Other results support the hypothesis that polymorphisms in different genes regulating iron metabolism may modulate penetrance of $H F E-H H . C Y B R D 1$ was shown to be a possible modifier gene of iron phenotype in patients with HFE-HH $[18,19]$ and, recently, the p.Ala736Val TMPRSS6 polymorphism was shown to be likely a modifier of $H F E-H H$ in a highly selected subgroup of male C282Y homozygotes [20].

We hypothesized that other common variants located in genes outside this pathway could modulate iron overload in HFE-HH. To identify these variants, we conducted a genome-wide association study in $518 \mathrm{C} 282 \mathrm{Y}$ homozygous HFE-HH patients from the tertiary referral centre of Rennes, France. The association between SNPs and 7 clinical and biochemical outcomes was examined and a replication study of candidate SNPs was conducted in a sample of 748 HFE-HH patients from 4 Italian and French centres. In this paper, we present the results of this GWAS study that is the largest conducted so far in HFE-HH patients. 


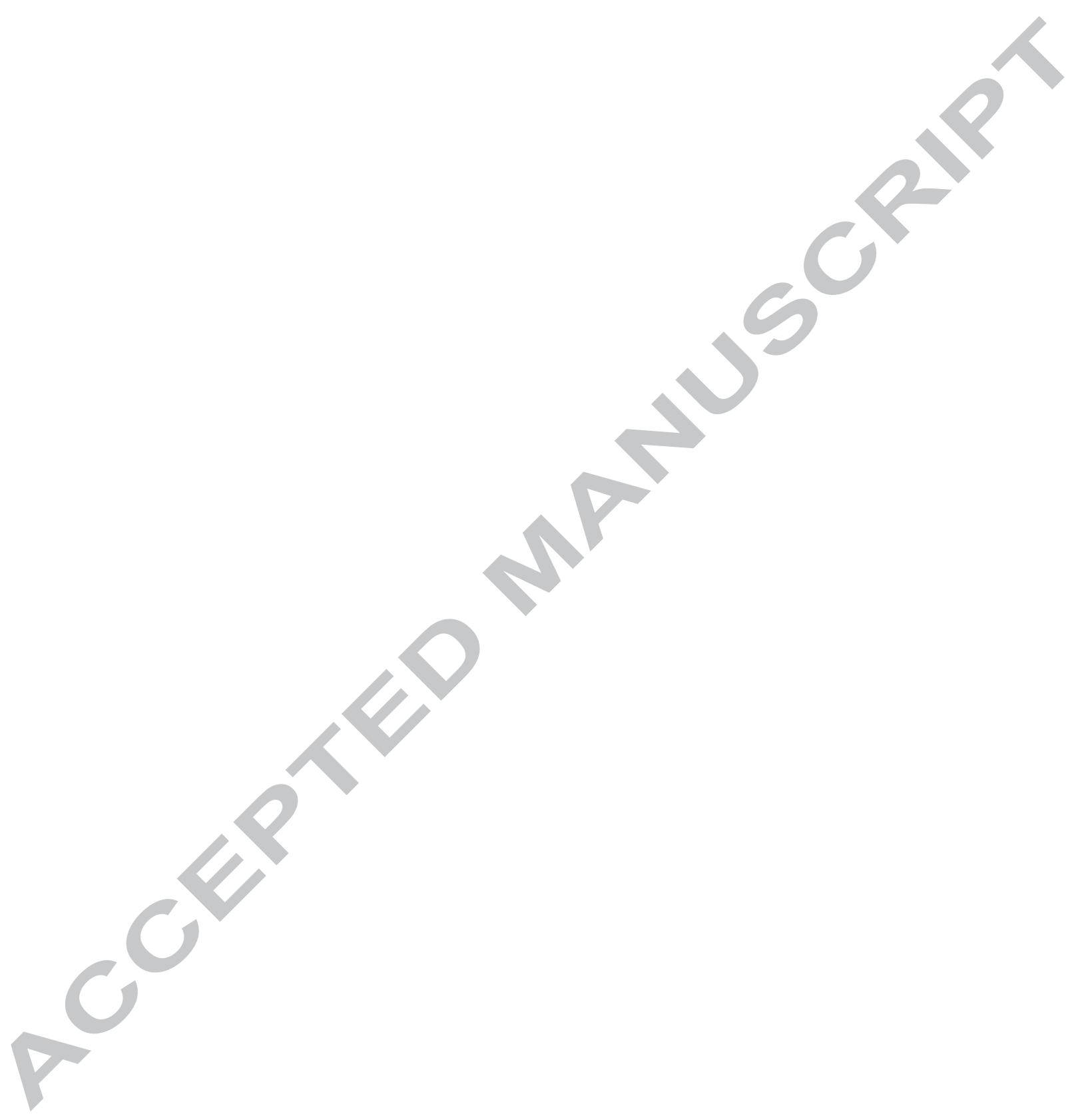




\section{Materials and Methods}

\section{Study population and replication sample}

Approval for the genome-wide association study was obtained from the local ethical committee (reference 09/10-722 - 23/03/2009). All participants gave written informed consent. Samples were collected thanks to the Logifer database comprising all C282Y homozygous probands and relatives referred to the Liver Unit in Rennes, France, and collected retrospectively before 1989 and, then, prospectively. According to French rules, Logifer was declared to the national committee "Informatics and Freedom" (CNIL). Data are recorded from patient's files by data-managers and keyboarded twice. A clinical research assistant provides quality control, and coherence control and statistical analysis are performed by a bio-statistician.

Selection criteria included availability of sex, age at diagnosis, serum ferritin level at diagnosis before any venesection therapy, amount of iron removed by phlebotomy and frozen DNA samples stored at $-20^{\circ} \mathrm{C}$ in the Centre of Biological Resources of Rennes. Carriers of the H63D mutation were excluded from this study. Of the 1730 C282Y homozygotes recorded in Logifer at the time of the study, 518 fulfilled these criteria. Replication for SNPs identified from the GWAS was conducted in 748 C282Y homozygous patients with informed consent from four different European Centres: Toulouse in Southern France $(n=279)$, Brest and Rennes in Brittany $(n=226$ and $n=124$, respectively), and Monza in Northern Italy $(n=119)$. Seven clinical and biochemical outcomes were examined: serum transferrin concentration, serum iron, serum ferritin, transferrin saturation, amount of iron removed by phlebotomy, liver fibrosis, and mixed biochemical and clinical score referred as the HAS score (Haute Autorité de Santé) [21]. All clinical and biochemical data were recorded at the time of diagnosis before any venesection therapy. Table 1 presents the characteristics of all the samples included in the GWAS and replication studies.

Liver fibrosis was assessed using the Metavir scoring system when liver biopsy was available $(n=227)$ [22]. Patients were classified as having severe fibrosis when the Metavir score was either F3 or F4. In the absence of liver biopsy, according to Guyader's algorithm, severe liver fibrosis was considered as absent when serum 
ferritin was < $1000 \mu \mathrm{g} / \mathrm{L}$. HAS score [21] ranged from 0 to 4 according to the absence/presence of increased transferrin saturation (stage 1), elevated serum ferritin levels (stage 2), iron-related functional symptoms (asthenia, distal arthralgia; stage 3) and iron-related organ damage (liver fibrosis, diabetes; stage 4). In addition, the following data, recorded at the time of diagnosis, were available for the Rennes GWAS cohort: alcohol consumption, tobacco smoking, medicinal iron and drug intake, year(s) and number of blood donations, year(s) and number of pregnancies, age at menopause, weight and height, blood pressure, common blood tests including serum cholesterol, triglycerides, ASAT, ALAT, glucose, uric acid, creatinine, and HCV antibody and HBs antigen (negative in all patients).

\section{Laboratory Methods}

We determined iron status by measuring the levels of serum iron ( $\mathrm{mmol} / \mathrm{L}$ ), transferrin saturation with iron (\%) and serum ferritin ( $\mu \mathrm{g} / \mathrm{L})$. Amount of iron removed (g) was assessed from the volume of blood extracted during initial depletion therapy until the achievement of low body iron stores (serum ferritin $\leq 50$ ), assuming that 500 $\mathrm{ml}$ of blood contains $250 \mathrm{mg}$ of elemental iron. For patients that were not subject to phlebotomy because of the absence of significant iron overload, it was assumed to be 0 . Genomic DNA was extracted from peripheral blood cells by the phenolchloroform method or by use of the Flexigen DNA kit (Qiagen). Only DNA samples with quality in accordance with Illumina recommendations were kept.

\section{Genome-wide genotyping and quality control procedures}

GWAS was performed on the 518 cases with the Illumina ${ }^{\mathrm{TM}}$ InfiniumHD technology (Human660W-Quad). A total of 657,366 markers were assessed for quality. Quality control tests were carried out using the GenABEL library [23] of the R statistical package (http://www.r-project.org/). The quality control flow diagram is presented in supplementary Fig. 1. Quality control assessments resulted in the exclusion of 95,988 CNV markers and 27,165 SNPs because of at least one of the following criteria: a minor allele frequency less than $1 \%$, a call rate less than $95 \%$, or rejection of Hardy-Weinberg equilibrium (HWE) at p-value equal to $10^{-6}$. Thirty-one samples were excluded from the analysis due to a call rate $<99 \%$, too high autosomal 
heterozygosity (FDR $<1 \%$ ), an average identity-by-state (IBS) value $>0.2$, or misclassification of sex. Iterative principal component analyses (PCA) of a matrix of IBS distances computed from the SNP genotype data excluded 13 patients as heterogeneous in ancestry or outliers. After filtering of SNPs and samples, there were 534,213 SNPs available for analysis in a sample of 474 cases. Genetic population structure was assessed by PCA thanks to the OriginMineR R package. [24]

Genotyping and quality control procedures for replication samples

Replication for SNPs identified from the GWAS was carried out by custom Fluidigm SNPtype assays based on allele-specific PCR SNP detection chemistry and designed for the BioMark HD System. Each sample was assessed for completeness of data $(>90 \%)$ and genotype data were assessed for deviation from HWE $\left(p<10^{-6}\right)$, minor allele frequency $(>5 \%)$ and completeness (>99\%).

\section{Statistical analyses}

Statistical analyses of the GWAS genotype data were carried out using the GenABEL $\mathrm{R}$ library for genome-wide association analysis [23]. The quantitative iron status outcomes were analysed using linear regression after rank-based inverse normal transformation to avoid inflated type I error resulting from departure from normality. Genotypes were coded as 0,1 or 2, indicating the number of copies of the less frequent of the two alleles in the genotype. The regression models for all outcomes included the additive genotype term and the covariates: age, with consideration of age groups of 10 years, and sex. Population stratification was also taken into account by adjusting models for the two principal components obtained from the PCA of the whole genotype data. For liver fibrosis, logistic regression was performed and we used ordered logistic regression (R cran function, polr) to model HAS-score. For the replication phase, a four-level factor indicating the centre where the sample was collected was added to each model instead of the principal components. As we conducted several analyses using different phenotypes and performed 8 * 534,213 
tests in our entire GWA analysis, we considered p-values $<10^{-8}\left(0.05 / 4.3 \times 10^{6}\right)$ to indicate genome-wide significance in our study.

The 20 SNPs tested in the replication study consisted of (i) SNPs with $P<10^{-6}$ from which only two SNPs were selected by LD block (Table 2), and, (ii) SNPs with $P<10^{-5}$ and $P>10^{-6}$ with one SNP being selected for each LD block to avoid redundancy (Supplementary Table 1).

\section{Genotype imputation}

Data were imputed for over 10 million SNPs using data from the 1000 Genomes Project [25]. Genotypes were aligned to the positive strand in both imputation and genotyping. SHAPEIT2 [26] and IMPUTE2 [27] were used for imputation of nongenotyped SNPs in the Illumina Human660W-Quad chips. We removed SNPs with minor allele frequency less than $1 \%$ and impute info measure less than 0.8 . Genomewide association analyses were conducted using SNPtest [27]. 


\section{Results}

\section{Characteristics of patients}

The clinical and biological characteristics of patients belonging to the primary and replication cohorts are reported in Table 1. With respect to primary cohort, additional descriptive data were as follows: BMI (men: 25.15 \pm 3.27 , women: $24.25 \pm 4.5$ ), excessive alcohol consumption (men: 16\%, women: 5\%), tobacco consumption (men: $31 \%$, women:15\%), blood donation (men: $23 \%$, women: $21 \%$ ), proportion of pregnancies (none $=17 \%$, one or 2 : $37 \%$, greater than $3: 24.5 \%$ ), number of menopausal women (44\%). Link between biological iron data and these putative modifying factors was investigated using both univariate and multivariate Gaussian regression models. Alcohol consumption was strongly associated with body iron $(p=0.004)$ and serum ferritin $\left(p=6 \times 10^{-7}\right)$ in univariate analyses. This association remains significant only with serum ferritin in a multivariate analysis including gender and age. In women, pregnancy and menopause were associated with body iron $(p=0.04$ and $p=0.02$, respectively), serum ferritin ( $p=0.04$ and $p=0.01$, respectively) and serum iron (NS and $p=0.002$, respectively) in univariate analyses only. Thus, GWAS was performed with regression including age and sex as only covariates. For ferritin, an analysis including also alcohol consumption was performed.

\section{Genome-wide Association Study}

The sequencing of the HFE gene confirmed that all participants were homozygous for the p.Cys282Tyr mutation and did not carry any other mutation in this gene known to be involved in $\mathrm{HH}$. Following quality control, a total of 534,213 SNP and 474 patients were included in the GWAS (supplementary Fig. 1). All HFE-HH patients were identified as being from European ancestry and particularly from Western Europe (supplementary Fig. 2).

Figure 1 shows the Manhattan plot obtained for GWAS of all the seven clinical and biochemical outcomes. P-values $<10^{-6}$ were obtained for ten SNPs on chromosomes 2, 3, 6, 16 and 9 (Table 2) and 41 SNPs were found associated with at least one of the seven outcomes with $p$-values between $10^{-6}$ and $10^{-5}$ (Supplementary Table 1 and Supplementary Fig. 3). However, GWAS analyses identified only one locus reaching the genome-wide significance threshold of $10^{-8}$ (Figure 2). This locus associated with serum transferrin concentration was located on chromosome 3q22 
(TF gene; rs3811647, intron 11, p-value $\left.=7 \times 10^{-9}\right)$. This SNP was also associated with serum iron $\left(p\right.$-value $\left.=4.9 \times 10^{-6}\right)$ but not associated with other phenotypic descriptors. The effect of rs3811647 was additive with each $A$ allele increasing both serum transferrin and serum iron concentration. It explained $7.7 \%$ of the variance of serum transferrin concentration and $4.7 \%$ of the variance of serum iron levels. Other potential associations were found between serum ferritin and rs3849200 on chromosome 6p16.3 (p-value $\left.=6.2 \times 10^{-7}\right)$ and rs4544229 on chromosome $16 q 21$ (pvalue $=8.9 \times 10^{-7}$ ), between the amount of iron removed and rs4371141 (VAV2 gene) on chromosome $9 q 34\left(p\right.$-value $\left.=9.4 \times 10^{-7}\right)$, and between the HAS-score and rs3900546 located between LOC644013 and MAP4K4 on chromosome 2 ( $p$-value $=$ $\left.2 \times 10^{-7}\right)$. Associations between serum ferritin and rs3849200 and rs4544229 were conserved when alcohol consumption was included in the regression model.

\section{Follow-up Association Study}

In the second phase, twenty SNPs were selected for validation on an independent sample of 748 patients. Iron parameters distributions for patients included in the replication study are presented Table 1. Data distributions were compared between centres with linear models adjusted by age and gender (Supplementary Fig. 4). Raw iron parameters were found to vary significantly between centres (Supplementary Fig. 4 and 5A) but differences between centres were clearly reduced after rank-based inverse normal transformations (Supplementary Fig. 5B). After quality controls, a total of 18 SNPs were retained for replication, rs3849200 and rs2810493 being removed because of no call rate. Among these SNPs, only rs3811647 in the TF gene showed evidence for association with both serum transferrin and serum iron with $p$-values of $5 \times 10^{-13}$ and $3.6 \times 10^{-6}$, respectively (Supplementary Table 2).

\section{Association Analysis of Combined GWAS and Follow-up Samples}

The GWAS and follow-up study data were combined ( $n=1220$ patients) and were analysed for each outcome in a model that included age, sex, the collection centre variable and a variable to indicate if patients were from the GWAS or the follow-up study. Results are presented in Supplementary Table 3. Genome-wide significance was found for the association of rs3811647 in the TF gene with serum transferrin ( $p$ - 
value $\left.=1 \times 10^{-20}\right)$ and serum iron $\left(p\right.$-value $\left.=9.24 \times 10^{-11}\right)$. Besides these strong associations, no significant direct association with other phenotypic descriptors was found. Four other loci show potential association signals but with low significance ( $p$ value around $10^{-3}$ ): rs10788066, located between the PPAPDC1A and SEC23IP genes, with serum ferritin, amount of iron removed, severe liver fibrosis, and HASscore; rs2941832, near the gene SALL3, with serum ferritin and amount of iron removed; rs2810473 and rs4406471 in the VAV2 gene with serum ferritin and, to a lesser extent, amount of iron removed, and rs17012214, located within the gene TTC27, with severe liver fibrosis.

As the role of TMPRSS6 has been highly documented in iron metabolism in the last few years [29-33], we also assessed, in the combined cohort, the association of the 7 outcomes with two common variants in TMPRSS6 (rs855791 and rs4820268). Using the same models, we found weak signals of association with the HAS-score for both SNPs (rs855791, $\mathrm{p}$-value $=1 \times 10^{-4}$ and rs4820268, $\mathrm{p}$-value $=6 \times 10^{-4}$ ), and with the amount of iron removed for rs4820268 only ( $p$-value $\left.=4 \times 10^{-4}\right)$. No association was detected with other parameters of iron status.

rs3811647 genotypes in the general population

We investigate the frequency of rs3811647 alleles from genotyping data obtained in a non-HFE population from Brittany $(n=191)$. We found that $A$ allele has frequency of 0.343 ( $A A, n=21, A G, n=89 ; G G, n=81$ ). We compared allele frequency in the population of $\mathrm{C} 282 \mathrm{Y}$ homozygous patients against this population of Brittany and against GBR and CEU from 1000 Genomes and did not find any difference (chisquared test).

Clinical, biochemical, and rs3811647 genotype correlations

Clinical and biochemical parameters were investigated in relation with rs3811647 genotypes in patients included in the GWAS study. Except for the additive effect of rs3811647, with each $A$ allele increasing both serum transferrin and serum iron concentration, no significant influence of the rs3811647 genotype on clinical and other biochemical parameters was found (Table 3a). However, significant positive associations were detected between serum transferrin and serum iron levels and 
between serum iron levels and all phenotypic outcomes studied. Serum transferrin levels were negatively correlated with all other phenotypic markers except fibrosis (Table 3b). 


\section{Discussion}

In this paper, we report the first study designed at the genome-wide scale to identify SNPs associated with clinical and biochemical expression of HFE-hemochromatosis. This study was performed in a large sample of well-defined C282Y homozygous patients, totalizing more than 1,200 individuals presenting with a wide range of phenotypic expression. No significant association was found between SNPs and clinical outcomes. With respect to biochemical outcomes, only one chromosomal region including the rs3811647 SNP in the TF gene showed clear evidence for association with serum transferrin in the GWAS $\left(p\right.$-value $\left.=7 \times 10^{-9}\right)$, in the replication study $\left(p\right.$-value $\left.=5 \times 10^{-13}\right)$ and the combined analysis $\left(p\right.$-value $\left.=1 \times 10^{-20}\right)$. Unexpectedly, this SNP was also clearly associated with serum iron, and therefore indirectly linked to biochemical and clinical outcomes.

Notably, in the general population, rs3811647 was reported as associated with serum transferrin but not with serum iron [33-35] contrary to what we found in hemochromatosis patients. It is possible that, in the general population, the power of detecting association with serum iron was compromised by the limited range of the values of this parameter. In contrast, our sample of C282Y homozygotes is a combination of biochemically expressing and non-expressing individuals. The necessarily wider range of serum iron in these patients may have allowed us to highlight the role of rs3811647 genotype in modulating not only serum transferrin but also serum iron levels.

However, our study did not find a direct link between the rs3811647 SNP in the TF gene and the phenotypic presentation of $\mathrm{HH}$. Indeed, although this SNP was associated with serum iron, it was not significantly associated with serum ferritin, transferrin saturation, or any of the clinical outcomes tested. Indirect tests of associations are less powered than direct tests and may require much larger sample sizes than the ones used in this study to allow us to demonstrate a possible influence of the genotype at rs3811647 on other parameters of disease severity. However, we cannot exclude that such an association exists in HFE hemochromatosis only 
through the dysregulation of iron cellular efflux secondary to the impairment of hepcidin expression (Figure 3).

Our study indicates that the association of rs3811647 with serum transferrin concentration is maintained in C282Y homozygous patients and that the lowest serum transferrin levels are observed in those bearing the GG genotype. However, even the patients with the rs3811647 AA genotype have less serum transferrin than normal controls polymorphism (data not shown). This finding fits with the common observation of decreased serum transferrin levels in C282Y homozygotes, which is attributed to the preservation of a physiologic negative feedback of transferrin synthesis by elevated body iron stores. This could contribute to aggravate the iron burden through the increase of transferrin saturation and the consecutive increase of non-transferrin bound iron, which is considered as the main factor of visceral iron loading in hemochromatosis. However, although they had lower serum transferrin levels, patients with the rs3811647 GG genotype had no increased transferrin saturation when compared to other patients. This is in line with the concomitant decrease in serum iron levels, and could suggests that transferrin levels, as determined by rs3811647 polymorphisms, may participate per se in the regulation of systemic iron, possibly through a direct interaction with the molecular cascade involved in hepcidin production. [37]

We took advantage of this study to investigate putative candidate genes selected from literature and/or coding for molecules involved in iron-related metabolic pathways and previously identified GWAS-significant SNPs (Supplementary Table 4 and Supplementary Table 5). No association, even borderline, was found. Finally, we focused on TMPRSS6, a modifier gene identified by Valenti et al. in a highly selected population of 96 non-alcoholic male C282Y homozygotes [20]. In the subset of 230 non-alcoholic male C282Y homozygotes from the GWAS sample, an association was detected with SNPs located in this gene at the $1 \%$ nominal level ( $p$-value $=0.006$ with $\mathrm{AIR}$ ), but this association did not resist multiple testing corrections at the genome-wide level. It remains possible that TMPRSS6 acts as a modifier-gene but with a weak effect compared to age and sex. $\mathrm{HH}$ is a long-standing disease whose diagnosis is made at adulthood. Along the constitution of iron excess, many factors 
are able to act, at various periods and in opposite directions, resulting in highly variable iron burden from an individual to another. These factors include, apart blood donation, pregnancies and menopause that are easy to take into account and to quantify, regimen, drugs (including iron auto-medication), menstrual blood loss, alcohol consumption and evolution of metabolic features that are difficult to reliably assess over a long period. This highlights the need for better controlling environmental factors, not only alcohol consumption, which implies to study much larger population than in the present GWAS.

The present study suffered from several limitations. First, the phenotypic description of $\mathrm{HH}$ remains difficult and imprecise. Two types of indicators are available: those measuring the iron burden and those assessing organ damage. The degree of iron burden is usually deduced, at the time of diagnosis, from serum ferritin levels, hepatic iron concentration assessed either by biochemical determination or magnetic resonance imaging, histological semi-quantitative evaluation of hepatic iron stores, and, to a lesser extent, transferrin saturation. However, all these indicators have to be interpreted according to age and gender and are subject to frequent limitations. Conditions that often coexist in hemochromatosis and may result in overestimation of iron burden can modify serum ferritin levels (i.e. excessive alcohol intake, metabolic syndrome, cell necrosis and inflammatory syndrome). Because it requires an invasive approach, histological and biochemical determination of hepatic iron concentration is less and less performed. It also depends on both liver volume and hepatic iron distribution that may be heterogeneous, especially in case of cirrhosis. Hepatic iron concentration measurement by $\mathrm{MRI}$ is reliable within the range of $60-300 \mu \mathrm{mol} / \mathrm{g}$ of dry liver only, which precludes correct assessment of iron burden in patients with early and late hemochromatosis. Finally, transferrin saturation is a rough indicator of iron burden because it is usually rapidly complete regardless of excess iron amount. Then, we chose to select only patients with amount of iron removed (AIR) available, since AIR is considered as the most reliable means to assess iron burden. However, because AIR is retrospective and often difficult to calculate, numerous C282Y homozygotes of the cohort were lost for inclusion. Indicators of organ damage allow for a precise case description, but the non-specificity of most clinical symptoms and high prevalence of co-damaging factors, such as metabolic syndrome and alcohol, 
may result in overestimating the role of iron in the clinical presentation. Second, the present study may have been underpowered due to the limited number of cases for a GWAS ( $n=474$ from the 518 eligible cases) and to the few participants with low or normal body iron stores. Because the frequency of HFE C282Y homozygotes is very low, collecting enough sample size for such a study design to detect variants with moderate effect size is a challenge. Alternative strategy might be needed, such as conducting GWAS of iron status in the general population and then test the identified loci in the C282Y homozygous patients. Large genome-wide studies in which the authors looked for loci controlling serum iron, serum transferrin, transferrin saturation and serum ferritin in the general population have been published recently [33-35]. Although performed on large sample sizes, these studies did not provide evidence for variants with significant effects on any of the parameters examined, except for variants in the HFE and TMPRSS6 genes that were controlling serum iron, and variants in $T F$ that were controlling serum transferrin. In this study we found that, in addition to being associated with serum transferrin, the same variants in the TF gene were also associated with serum iron in hemochromatosis patients. If we consider less stringent p-values, the variants in TMPRSS6 can also be considered as marginally associated with some of the iron burden parameters in this sample of hemochromatosis patients. The success rate of this strategy is therefore quite good, but there were not many variants segregating with iron burden in the general population. In addition, it is also possible that different variants control iron parameters in the general population and in hemochromatosis patients, which motivated this particular study. Unfortunately, the C282Y mutation is not routinely screened in the general population, and only few participants with low or normal parameters of iron burden are included in our GWAS study. Therefore, the power of this study is probably compromised to some extent by the limited range of expression of these parameters. Although large-scale studies in the general population could help identify such C282Y homozygotes with low or normal iron parameters, it should be remembered that the frequency of this genotype is only $3-5 / 1000$, and obtaining a number of non-penetrant cases from the same area sufficient to increase the power of this study is unrealistic for the moment. The third limitation is the lack of suitable information about environmental factors. For example, data on regimen with respect to daily iron intake and tea consumption were missing in the database. However, data on alcohol consumption, tobacco smoking, blood donation, and, in females, 
number of pregnancies and menopause status were collected and analyzed. We did not find significant association when taking alcohol consumption into account but samples sizes were probability too small to detect possible gene-environment interactions. Fourth, although a large number of SNPs were tested $(n=534,213)$, the present study was far from covering all putative genetic variants able to act as modifiers of iron burden and/or organ damage. Using the SNP-chip data, we investigated the possible role of CNV and did not find any association. However, we were not able to investigate low frequency and rare variants that are not targeted nor tagged by the SNP-chip. We thus cannot exclude based on our results the involvement of one or more modifier genes but we can rule out the role of common variants with large effect outside the TF gene.

In conclusion, our results indicate that, in C282Y/C282Y HFE-HH, the rs3811647 polymorphism in the TF gene continues to regulate serum transferrin levels and is unexpectedly associated with serum iron levels. Our study also demonstrates a potential indirect but weak link, through serum iron levels, between the rs3811647 polymorphism and the clinical and biological expression of the disease. Finally it shows, by contrast to candidate gene studies, that, in an unselected and large population of $\mathrm{C} 282 \mathrm{Y}$ homozygotes, i.e. in "true life", there is no other common polymorphism exerting a significant phenotypic effect. At this stage, the role of rare and low frequency variants that are not tagged by SNP-chips remains to be investigated. Next-generation sequencing technologies will enable to explore their role and determine if there exist some rare mutations with clinical significance in $\mathrm{HFE}-\mathrm{HH}$. In designing exome or whole genome sequencing studies, it will however be important to carefully select patients and to control for environmental factors.

\section{Acknowledgements}

The authors are indebted to the medical doctors and the nurse staff of the Liver Unit and to the Centre de Ressources Biologiques of the Rennes University Hospital. They acknowledge all the patients for accepting to participate in the study. The 
authors would also like to acknowledge Michelle Perrin (Inserm CIC 0203) and Jeff Morcet (Inserm CIC 0203) for managing quality control and statistical analysis of the Rennes Logifer database, Laura Pages (Inserm U1043) for collecting clinical data on the patients, Céline Besson-Fournier (Inserm U1043) for preparing the DNA samples, Frédéric Martins and Jean-José Maoret (GeT Platform, Genotoul) for running the SNPtype assays, and Pr. Jean-Pierre Vinel (Hepatogastroenterology Unit, $\mathrm{CHU}$ Purpan, Toulouse) for his support. We thank Pr. W. Bodmer and the People of the British Isles project for the genotyping of controls from Brittany. 


\section{References}

[1] Liver, E. A. F. T. S. O. T. (2010), 'EASL clinical practice guidelines for HFE hemochromatosis.', J Hepatol 53(1), 3--22.

[2] Allen, K. J.; Gurrin, L. C.; Constantine, C. C.; Osborne, N. J.; Delatycki, M. B.; Nicoll, A. J.; McLaren, C. E.; Bahlo, M.; Nisselle, A. E.; Vulpe, C. D.; Anderson, G. J.; Southey, M. C.; Giles, G. G.; English, D. R.; Hopper, J. L.; Olynyk, J. K.; Powell, L. W. \& Gertig, D. M. (2008), 'Iron-overload-related disease in HFE hereditary hemochromatosis.', N Engl J Med 358(3), 221--230.

[3] Adams, L. A.; Angulo, P.; Abraham, S. C.; Torgerson, H. \& Brandhagen, D. (2006), 'The effect of the metabolic syndrome, hepatic steatosis and steatohepatitis on liver fibrosis in hereditary hemochromatosis.', Liver Int 26(3), 298--304.

[4] Beutler, E.; Felitti, V. J.; Koziol, J. A.; Ho, N. J. \& Gelbart, T. (2002), 'Penetrance of 845G--> A (C282Y) HFE hereditary haemochromatosis mutation in the USA.', Lancet 359(9302), 211--218.

[5] Deugnier, Y.; Jouanolle, A.; Chaperon, J.; Moirand, R.; Pithois, C.; Meyer, J.; Pouchard, M.; Lafraise, B.; Brigand, A.; Caserio-Schoenemann, C.; Mosser, J.; Adams, P.; Gall, J. L. \& David, V. (2002), 'Gender-specific phenotypic expression and screening strategies in C282Y-linked haemochromatosis: a study of 9396 French people.', Br J Haematol 118(4), 1170--1178.

[6] Jackson, H. A.; Carter, K.; Darke, C.; Guttridge, M. G.; Ravine, D.; Hutton, R. D.; Napier, J. A. \& Worwood, M. (2001), 'HFE mutations, iron deficiency and overload in 10,500 blood donors.', $\mathrm{Br} J$ Haematol 114(2), 474--484.

[7] Adams, P. C.; Reboussin, D. M.; Barton, J. C.; McLaren, C. E.; Eckfeldt, J. H.; McLaren, G. D.; Dawkins, F. W.; Acton, R. T.; Harris, E. L.; Gordeuk, V. R.; Leiendecker-Foster, C.; Speechley, M.; Snively, B. M.; Holup, J. L.; Thomson, E.; Sholinsky, P.; Hemochromatosis \& Investigators, I. O. S. (H. S. R. (2005), 'Hemochromatosis and iron-overload screening in a racially diverse population.', $N$ Engl $J$ Med 352(17), 1769--1778.

[8] Andersen, R. V.; Tybjaerg-Hansen, A.; Appleyard, M.; Birgens, H. \& Nordestgaard, B. G. (2004), 'Hemochromatosis mutations in the general population: iron overload progression rate.', Blood 103(8), 2914--2919.

[9] Beutler, E. (1997), 'The significance of the 187G (H63D) mutation in hemochromatosis.', Am J Hum Genet 61(3), 762--764.

[10] Guyader, D.; Jacquelinet, C.; Moirand, R.; Turlin, B.; Mendler, M. H.; Chaperon, J.; David, V.; Brissot, P.; Adams, P. \& Deugnier, Y. (1998), 'Noninvasive prediction of fibrosis in C282Y homozygous hemochromatosis.', Gastroenterology 115(4), 929--936.

[11] Livesey, K. J.; Wimhurst, V. L. C.; Carter, K.; Worwood, M.; Cadet, E.; Rochette, J.; Roberts, A. G.; Pointon, J. J.; Merryweather-Clarke, A. T.; Bassett, M. L.; Jouanolle, A.; Mosser, A.; David, V.; Poulton, J. \& Robson, K. J. H. (2004), 'The 16189 variant of mitochondrial DNA occurs more frequently in $\mathrm{C} 282 \mathrm{Y}$ homozygotes with haemochromatosis than those without iron loading.', J Med Genet 41(1), 6--10.

[12] Beutler, E.; Beutler, L.; Lee, P. L. \& Barton, J. C. (2004), 'The mitochondrial nt 16189 polymorphism and hereditary hemochromatosis.', Blood Cells Mol Dis 33(3), 344--345.

[13] Jacolot, S.; Gac, G. L.; Scotet, V.; Quere, I.; Mura, C. \& Ferec, C. (2004), 'HAMP as a modifier gene that increases the phenotypic expression of the HFE pC282Y homozygous genotype.', Blood 103(7), 2835--2840.

[14] Merryweather-Clarke, A. T.; Cadet, E.; Bomford, A.; Capron, D.; Viprakasit, V.; Miller, A.; McHugh, P. J.; Chapman, R. W.; Pointon, J. J.; Wimhurst, V. L. C.; Livesey, K. J.; Tanphaichitr, V.; Rochette, J. \& Robson, K. J. H. (2003), 'Digenic inheritance of mutations in HAMP and HFE results in different types of haemochromatosis.', Hum Mol Genet 12(17), 2241--2247. 
[15] Le Gac, G.; Scotet, V.; Ka, C.; Gourlaouen, I.; Bryckaert, L.; Jacolot, S.; Mura, C. \& Férec, C. (2004), 'The recently identified type $2 \mathrm{~A}$ juvenile haemochromatosis gene (HJV), a second candidate modifier of the C282Y homozygous phenotype.', Hum Mol Genet 13(17), 1913--1918.

[16] Milet, J.; Dehais, V.; Bourgain, C.; Jouanolle, A. M.; Mosser, A.; Perrin, M.; Morcet, J.; Brissot, P.; David, V.; Deugnier, Y. \& Mosser, J. (2007), 'Common variants in the BMP2, BMP4, and HJV genes of the hepcidin regulation pathway modulate HFE hemochromatosis penetrance.', Am J Hum Genet 81(4), 799--807.

[17] Milet, J.; Gac, G. L.; Scotet, V.; Gourlaouen, I.; Thèze, C.; Mosser, J.; Bourgain, C.; Deugnier, Y. \& Férec, C. (2010), 'A common SNP near BMP2 is associated with severity of the iron burden in HFE p.C282Y homozygous patients: a follow-up study.', Blood Cells Mol Dis 44(1), 34--37.

[18] Constantine, C. C.; Anderson, G. J.; Vulpe, C. D.; McLaren, C. E.; Bahlo, M.; Yeap, H. L.; Gertig, D. M.; Osborne, N. J.; Bertalli, N. A.; Beckman, K. B.; Chen, V.; Matak, P.; McKie, A. T.; Delatycki, M. B.; Olynyk, J. K.; English, D. R.; Southey, M. C.; Giles, G. G.; Hopper, J. L.; Allen, K. J. \& Gurrin, L. C. (2009), 'A novel association between a SNP in CYBRD1 and serum ferritin levels in a cohort study of HFE hereditary haemochromatosis.', Br J Haematol 147(1), 140--149.

[19] Pelucchi, S.; Mariani, R.; Calza, S.; Fracanzani, A. L.; Modignani, G. L.; Bertola, F.; Busti, F.; Trombini, P.; Fraquelli, M.; Forni, G. L.; Girelli, D.; Fargion, S.; Specchia, C. \& Piperno, A. (2012), 'CYBRD1 as a modifier gene that modulates iron phenotype in HFE p.C282Y homozygous patients.', Haematologica 97(12), 1818--1825.

[20] Valenti, L.; Fracanzani, A. L.; Rametta, R.; Fraquelli, M.; Soverini, G.; Pelusi, S.; Dongiovanni, P.; Conte, D. \& Fargion, S. (2012), 'Effect of the A736V TMPRSS6 polymorphism on the penetrance and clinical expression of hereditary hemochromatosis.', J Hepatol 57(6), 1319--1325.

[21] Brissot, P.; Troadec, M.; Bardou-Jacquet, E.; Lan, C. L.; Jouanolle, A.; Deugnier, Y. \& Loréal, O. (2008), 'Current approach to hemochromatosis.', Blood Rev 22(4), 195--210.

[22] Bedossa, P. \& Poynard, T. (1996), 'An algorithm for the grading of activity in chronic hepatitis C. The METAVIR Cooperative Study Group.', Hepatology 24(2), 289--293.

[23] Aulchenko, Y. S.; Ripke, S.; Isaacs, A. \& van Duijn, C. M. (2007), 'GenABEL: an R library for genome-wide association analysis.', Bioinformatics 23(10), 1294--1296.

[24] de Tayrac, M.; Babron M.C.; Génin E. (2012) 'OriginMiner : show me your genes and I'll tell you where you come from.' Presented at the 62nd Annual Meeting of The American Society of Human Genetics, November 7, 2012 in San Francisco, California.

[25] The 1000 Genomes Project Consortium. (2010). 'A map of human genome variation from population-scale sequencing.' Nature 467 (7319):1061-1073.

[26] O. Delaneau, J. Marchini, 'The 1000 Genomes Project Consortium (2014) Integrating sequence and array data to create an improved 1000 Genomes Project haplotype reference panel'. Nature Communications 53934

[27] Marchini J, Howie B, Myers S, McVean G, Donnelly P. (2007) 'A new multipoint method for genome-wide association studies by imputation of genotypes.' Nat Genet 39(7):906-13.

[28] Pruim, R. J.; Welch, R. P.; Sanna, S.; Teslovich, T. M.; Chines, P. S.; Gliedt, T. P.; Boehnke, M.; Abecasis, G. R. \& Willer, C. J. (2010), 'LocusZoom: regional visualization of genome-wide association scan results.', Bioinformatics 26(18), 2336--2337.

[29] Finberg, K. E.; Heeney, M. M.; Campagna, D. R.; Aydinok, Y.; Pearson, H. A.; Hartman, K. R.; Mayo, M. M.; Samuel, S. M.; Strouse, J. J.; Markianos, K.; Andrews, N. C. \& Fleming, M. D. (2008), 'Mutations in TMPRSS6 cause iron-refractory iron deficiency anemia (IRIDA).', Nat Genet 40(5), 569-571. 
[30] Du, X.; She, E.; Gelbart, T.; Truksa, J.; Lee, P.; Xia, Y.; Khovananth, K.; Mudd, S.; Mann, N.; Moresco, E. M. Y.; Beutler, E. \& Beutler, B. (2008), 'The serine protease TMPRSS6 is required to sense iron deficiency.', Science 320(5879), 1088--1092.

[31] Chambers, J. C.; Zhang, W.; Li, Y.; Sehmi, J.; Wass, M. N.; Zabaneh, D.; Hoggart, C.; Bayele, H.; McCarthy, M. I.; Peltonen, L.; Freimer, N. B.; Srai, S. K.; Maxwell, P. H.; Sternberg, M. J. E.; Ruokonen, A.; Abecasis, G.; Jarvelin, M.; Scott, J.; Elliott, P. \& Kooner, J. S. (2009), 'Genome-wide association study identifies variants in TMPRSS6 associated with hemoglobin levels.', Nat Genet 41(11), 1170--1172.

[32] Benyamin, B.; Ferreira, M. A. R.; Willemsen, G.; Gordon, S.; Middelberg, R. P. S.; McEvoy, B. P.; Hottenga, J.; Henders, A. K.; Campbell, M. J.; Wallace, L.; Frazer, I. H.; Heath, A. C.; de Geus, E. J. C.; Nyholt, D. R.; Visscher, P. M.; Penninx, B. W.; Boomsma, D. I.; Martin, N. G.; Montgomery, G. W. \& Whitfield, J. B. (2009), 'Common variants in TMPRSS6 are associated with iron status and erythrocyte volume.', Nat Genet 41(11), 1173--1175.

[33] Tanaka, T.; Roy, C. N.; Yao, W.; Matteini, A.; Semba, R. D.; Arking, D.; Walston, J. D.; Fried, L. P.; Singleton, A.; Guralnik, J.; Abecasis, G. R.; Bandinelli, S.; Longo, D. L. \& Ferrucci, L. (2010), 'A genome-wide association analysis of serum iron concentrations.', Blood 115(1), 94--96.

[34] Benyamin, B.; McRae, A. F.; Zhu, G.; Gordon, S.; Henders, A. K.; Palotie, A.; Peltonen, L.; Martin, N. G.; Montgomery, G. W.; Whitfield, J. B. \& Visscher, P. M. (2009), 'Variants in TF and HFE explain approximately $40 \%$ of genetic variation in serum-transferrin levels.', Am J Hum Genet 84(1), 60--65.

[35] Pichler, I.; Minelli, C.; Sanna, S.; Tanaka, T.; Schwienbacher, C.; Naitza, S.; Porcu, E.; Pattaro, C.; Busonero, F.; Zanon, A.; Maschio, A.; Melville, S. A.; Piras, M. G.; Longo, D. L.; Guralnik, J.; Hernandez, D.; Bandinelli, S.; Aigner, E.; Murphy, A. T.; Wroblewski, V.; Marroni, F.; Theurl, I.; Gnewuch, C.; Schadt, E.; Mitterer, M.; Schlessinger, D.; Ferrucci, L.; Witcher, D. R.; Hicks, A. A.; Weiss, G.; Uda, M. \& Pramstaller, P. P. (2011), 'Identification of a common variant in the TFR2 gene implicated in the physiological regulation of serum iron levels.', Hum Mol Genet 20(6), 1232--1240.

[36] Ruchala P, Nemeth E. (2014) 'The pathophysiology and pharmacology of hepcidin.' Trends Pharmacol Sci. 35(3):155-61.

[37] Finberg, K. E. (2013), 'Regulation of systemic iron homeostasis.', Curr Opin Hematol 20(3), 208-214 
Tables

Table 1 - Main clinical and demographic characteristics of the primary and replication cohorts

\begin{tabular}{|c|c|c|c|c|c|}
\hline & \multirow{2}{*}{ GWAS sample } & \multicolumn{4}{|c|}{ Replication samples } \\
\hline & & Rennes & Toulouse & Brest & Monza \\
\hline Sample size & 474 & 124 & 279 & 224 & 119 \\
\hline Gender (female) (male) & $(200)(274)$ & $(67)(57)$ & $(108)(171)$ & $(93)(133)$ & $(26)(93)$ \\
\hline Age at diagnosis (years) & $45 \pm 12$ & $44 \pm 14.2$ & $47 \pm 12$ & $46.0 \pm 13$ & $45 \pm 12.2$ \\
\hline Serum iron (mmol/l) & $34.5(29-39.3)$ & $34.00(29.34-38.90)$ & $35.6(30.4-40.8)$ & $36.0(31.0-41.0)$ & $36.43(33.48-39.55)$ \\
\hline NA's & 26 & 11 & 44 & 16 & 0 \\
\hline Serum Transferrin $(\mathrm{g} / \mathrm{L})$ & $1.80(1.60-2.00)$ & $1.88(1.60-2.01)$ & $1.78(1.60-2.03)$ & $1.77(1.60-2.00)$ & $1.83(1.58-2.06)$ \\
\hline NA's & 38 & 14 & 55 & 16 & 0 \\
\hline $\begin{array}{l}\text { Transferrin saturation } \\
(\%)\end{array}$ & $80(65-89)$ & $78(66.5-85.85)$ & $84(67-92)$ & $83(73-92)$ & $84(72-90)$ \\
\hline NA's & 28 & 10 & 35 & 0 & 33 \\
\hline AIR (g) & $4.7(2.1-8.2)$ & $3.8(1.7-7.8)$ & $6.1(3.5-11.2)$ & $4.1(2.12-6.8)$ & $6(4-10.75)$ \\
\hline NA's & 0 & 0 & 197 & 0 & 0 \\
\hline Serum ferritin $(\mu \mathrm{g} / \mathrm{L})$ & $776(446-1565)$ & $570(318-1136)$ & $1118(634-2315)$ & $688(370-995)$ & $1120(719-2374)$ \\
\hline NA's & 11 & 5 & 0 & 0 & 0 \\
\hline \multicolumn{6}{|l|}{ Fibrosis (grading) } \\
\hline no & 367 & 100 & 128 & 161 & 81 \\
\hline severe & 72 & 14 & 30 & 41 & 25 \\
\hline NA's & 35 & 10 & 121 & 22 & 13 \\
\hline \multicolumn{6}{|l|}{ HAS (grading) } \\
\hline 0 & 13 & 3 & 3 & 0 & 1 \\
\hline 1 & 44 & 12 & 10 & 0 & 3 \\
\hline 2 & 131 & 45 & 89 & 0 & 48 \\
\hline 3 & 164 & 32 & 141 & 0 & 39 \\
\hline 4 & 76 & 18 & 36 & 0 & 28 \\
\hline NA's & 46 & 14 & 0 & 224 & 0 \\
\hline
\end{tabular}

a Median value $\pm \mathrm{sd}$.

b Median value (25th-75th percentile).

* Amount of Iron Removed (weekly or bimonthly venesections until serum ferritin $<50 ; 1 \mathrm{~L}$ of blood $=0,5 \mathrm{~g}$ of iron)

$\mathrm{NA}=$ non available

Table 2. GWA Analyses results with P-values $<10^{-6}$

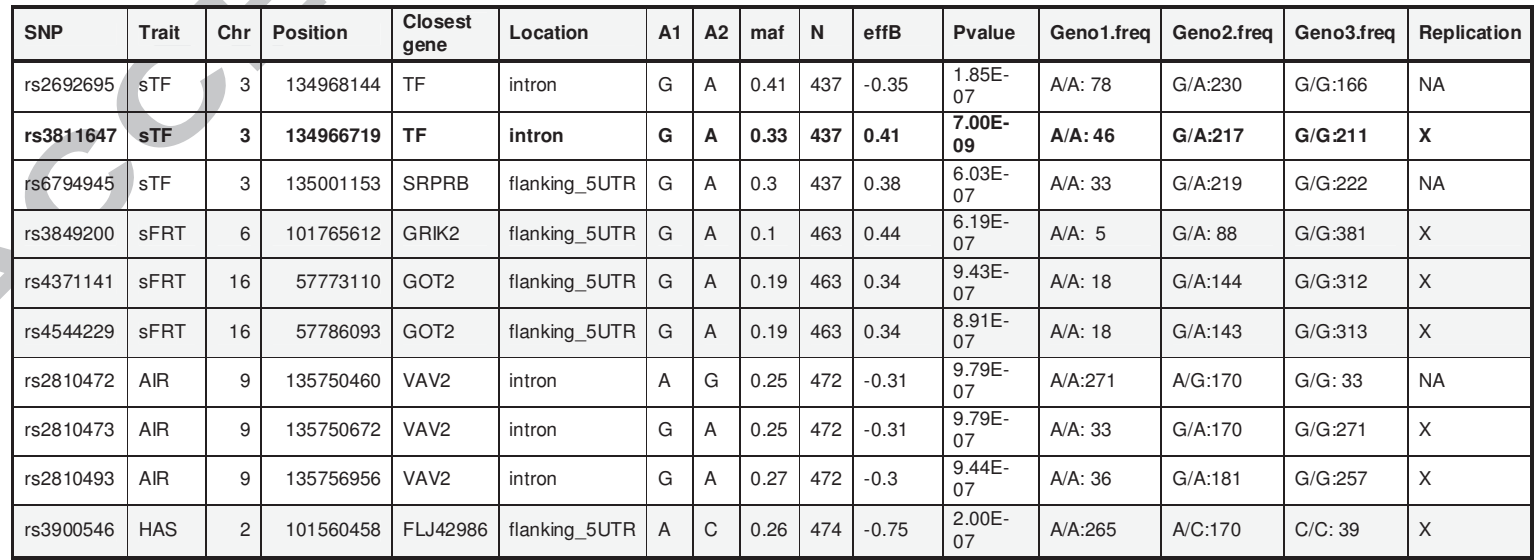

Abbreviations: $\mathrm{sTF}=$ serum transferrin concentration, $\mathrm{sFRT}=$ serum ferritin concentration, $\mathrm{AIR}=$ amount of iron removed, $\mathrm{HAS}=$ HAS score, A1= reference allele, A2: non-reference allele, maf=minor allele frequency, effB= Effect of the non-reference allele in allelic test. 
Table 3. rs3811647 genotypes, clinical and biochemical correlations

a.

\begin{tabular}{|c|c|c|c|c|c|c|c|}
\hline rs3811647 & Serum iron & Serum transferrin & $\begin{array}{l}\text { Transferrin } \\
\text { saturation }\end{array}$ & $\begin{array}{c}\text { Serum } \\
\text { ferritin }\end{array}$ & $\begin{array}{c}\text { Iron } \\
\text { removed }\end{array}$ & Fibrosis & HAS score \\
\hline AA & $\begin{array}{c}38.8 \pm 9.1 \\
(n=43)\end{array}$ & $\begin{array}{c}1.98 \pm 0.30 \\
(n=43)\end{array}$ & $\begin{array}{c}78.3 \pm 17.4 \\
(n=44)\end{array}$ & $\begin{array}{c}1632 \pm 1646 \\
(n=45)\end{array}$ & $\begin{array}{c}7.3 \pm 6.2 \\
(n=45)\end{array}$ & $\begin{array}{c}0.18 \pm 0.38 \\
(n=40)\end{array}$ & $\begin{array}{c}2.66 \pm 1.03 \\
(n=44)\end{array}$ \\
\hline AG & $\begin{array}{c}34.3 \pm 9.1 \\
(n=207)\end{array}$ & $\begin{array}{c}1.87 \pm 0.28 \\
(n=198)\end{array}$ & $\begin{array}{c}74.7 \pm 18.8 \\
(n=203)\end{array}$ & $\begin{array}{c}1145 \pm 1329 \\
(n=213)\end{array}$ & $\begin{array}{c}5.9 \pm 4.9 \\
(n=210)\end{array}$ & $\begin{array}{c}0.14 \pm 0.35 \\
(n=198)\end{array}$ & $\begin{array}{c}2.56 \pm 1.03 \\
(n=201)\end{array}$ \\
\hline GG & $\begin{array}{c}32.4 \pm 7.1 \\
(n=98)\end{array}$ & $\begin{array}{c}1.74 \pm 0.33 \\
(n=195)\end{array}$ & $\begin{array}{c}75.9 \pm 17.8 \\
(n=199)\end{array}$ & $\begin{array}{c}1296 \pm 1356 \\
(n=205)\end{array}$ & $\begin{array}{l}6.7 \pm 6.1 \\
(n=201)\end{array}$ & $\begin{array}{c}0.16 \pm 0.36 \\
(n=194)\end{array}$ & $\begin{array}{c}2.56 \pm 0.99 \\
(n=200)\end{array}$ \\
\hline
\end{tabular}

b.

\begin{tabular}{|c|c|c|c|c|c|c|c|}
\hline $\begin{array}{l}\text { Phenotypic } \\
\text { markers }\end{array}$ & Serum iron & Serum transferrin & $\begin{array}{l}\text { Transferrin } \\
\text { saturation }\end{array}$ & $\begin{array}{l}\text { Serum } \\
\text { ferritin }\end{array}$ & $\begin{array}{l}\text { Iron } \\
\text { removed }\end{array}$ & Fibrosis & HAS score \\
\hline Serum iron & & $r=0.257(n=436)$ & $\begin{array}{c}r=0.747 \\
(n=437) \\
p<0.0001\end{array}$ & $\begin{array}{c}r=0.279 \\
(n=445) \\
p<0.0001\end{array}$ & $\begin{array}{c}r=0.216 \\
(n=430) \\
p<0.0001\end{array}$ & $\begin{array}{c}r=0.165 \\
(n=411) \\
p=0.0008\end{array}$ & $\begin{array}{c}r=0.346 \\
(n=424) \\
p<0.0001\end{array}$ \\
\hline $\begin{array}{c}\text { Serum } \\
\text { transferrin }\end{array}$ & $r=\begin{array}{c}0.257(n=436) \\
p<0.0001\end{array}$ & & $\begin{array}{c}r=-0.388 \\
(n=436) \\
p<0.0001\end{array}$ & $\begin{array}{c}r=-0.081 \\
(n=433) \\
p<0.0001\end{array}$ & $\begin{array}{c}r=-0.123 \\
(n=419) \\
p=0.0118\end{array}$ & $\begin{array}{c}r=-0.025 \\
(n=402) \\
p=0.6115\end{array}$ & $\begin{array}{c}r=-0.126 \\
(n=414) \\
p=0.0104\end{array}$ \\
\hline $\begin{array}{l}\text { Transferrin } \\
\text { saturation }\end{array}$ & $r=\begin{array}{c}0.747(n=437) \\
p<0.0001\end{array}$ & $\begin{array}{c}r=-0.388 \\
(n=436) \\
p<0.0001\end{array}$ & & $\begin{array}{c}r=0.347 \\
(n=443) \\
p<0.0001\end{array}$ & $\begin{array}{c}r=0.339 \\
(n=429) \\
p<0.0001\end{array}$ & $\begin{array}{c}r=0.197 \\
(n=410) \\
p=0.0001\end{array}$ & $\begin{array}{c}r=0.437 \\
(n=424) \\
p<0.0001\end{array}$ \\
\hline
\end{tabular}

Correlations between semi-quantitative variables (fibrosis and HAS score) and quantitative variables were also performed using one-way analysis of variance and gave the same results. 
Figure Legends

Figure 1 - Manhattan plots displaying results from GWAS of quantitative iron burden indices and clinical outcomes of HFE-HH.

Genome-wide analyses were performed for quantitative iron burden indices (serum transferrin concentration, serum iron, transferrin saturation, amount of iron removed by phlebotomy, and serum ferritin), and clinical outcomes (severe liver fibrosis, and HAS-score). All the analyses were performed on 534,213 genotyped SNPs. Horizontal lines indicate a suggestive $p$-value threshold of $10^{-6}$.

Figure 2 - Regional plots for rs3811647 located within TF gene.

Regional plots for imputed results are presented for rs3811647 identified as the single locus reaching the genome-wide significance threshold of $10^{-8}$ : for A. serum transferrin concentration analysis ( $p$-value $=7 \times 10^{-9}$ ), and $B$. with pleiotropic effect on serum iron $\left(p\right.$-value $\left.=4.9 \times 10^{-6}\right)$. The rs3811647 SNPs is represented as a diamond. Other SNPs are gray scaled following their $r^{2}$ value with the most associated SNP. The blue line represents variation in recombination rate. Plots were generated by LocusZoom. [28]

Figure 3 - Regulation of hepcidin transcription through the bone morphogenetic protein (BMP) - Smad pathway.

Binding of holotransferrin to transferrin receptor 1 (TfR1) displaces HFE from TfR1 to TfR2. The HFE-TfR2 complex binds to a complex associating BMPs, BMP receptor (BMPR) and hemojuvelin (HJV). Neogenin and transmembrane serine protease 6 (TMPRSS6) modulate hepcidin transcription by cleaving HJV. Hepcidin acts by favoring the internalization and degradation of the transmembrane iron transporter, ferroportin (FRP), which results in decreasing the systemic biodisponiblity of iron. In HFE hemochromatosis, the C282Y mutation impairs the migration of HFE to the cell membrane and thus the activation of the BMP - BMPR- HJV complex. This results in the preservation of FRP at the cell membrane and thus a high iron efflux. [36] 


\section{ACCEPTED MANUSCRIPT}

Transterrin

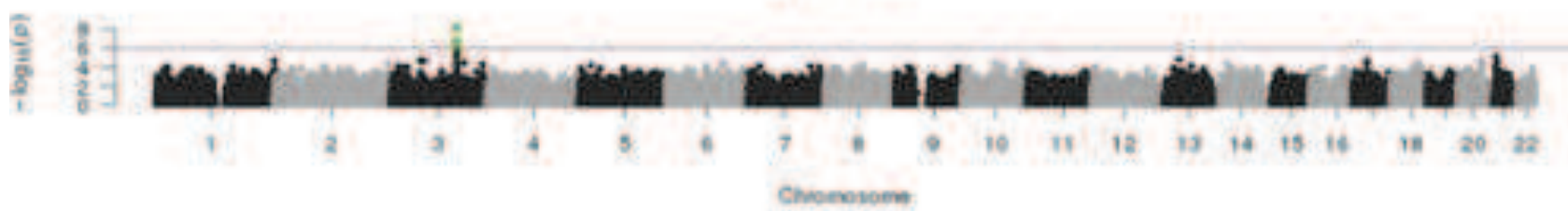

Serum iren

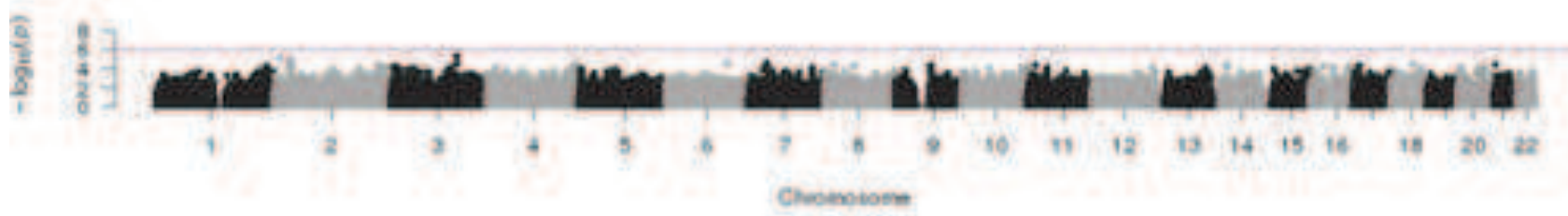

Transterrin Saturation

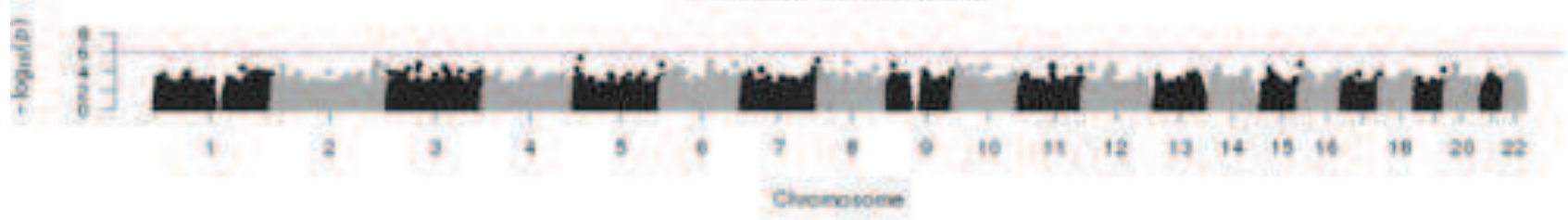

Amount of Iron Removed

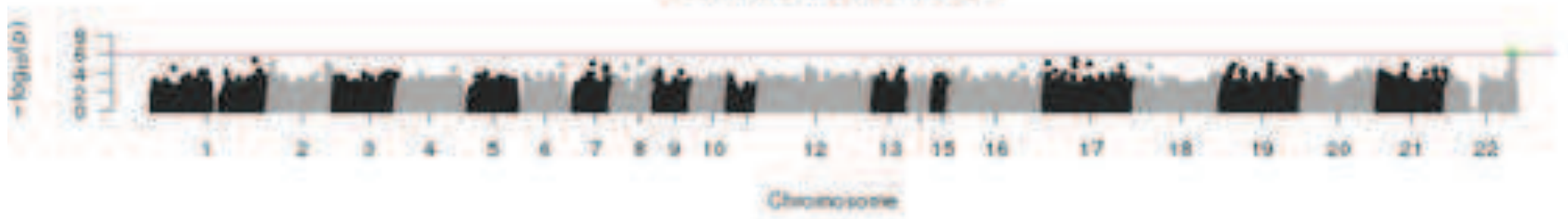

Serum feeritin

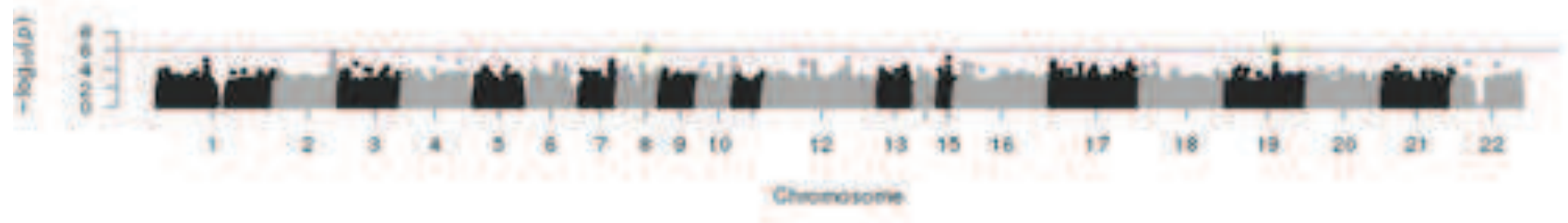

Fibresis

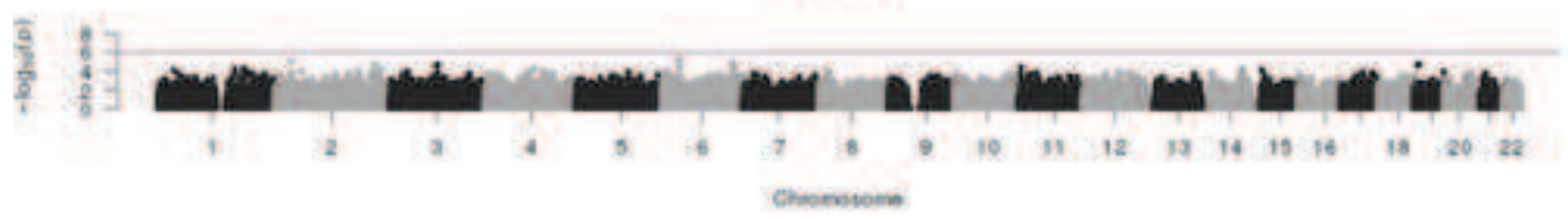

HAS seore

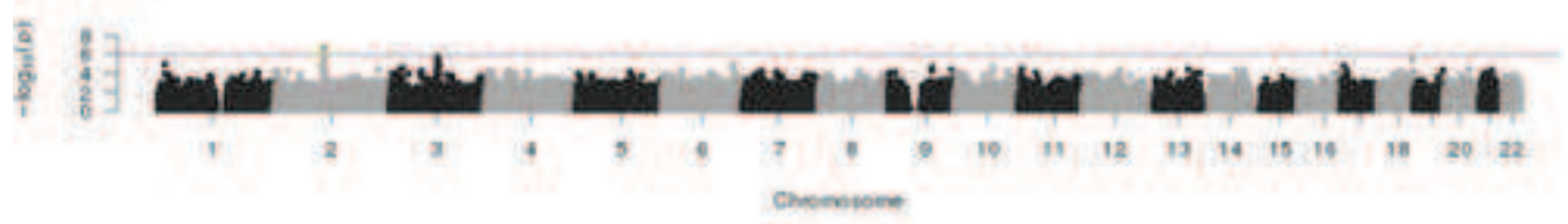


A.

Plotod SNP

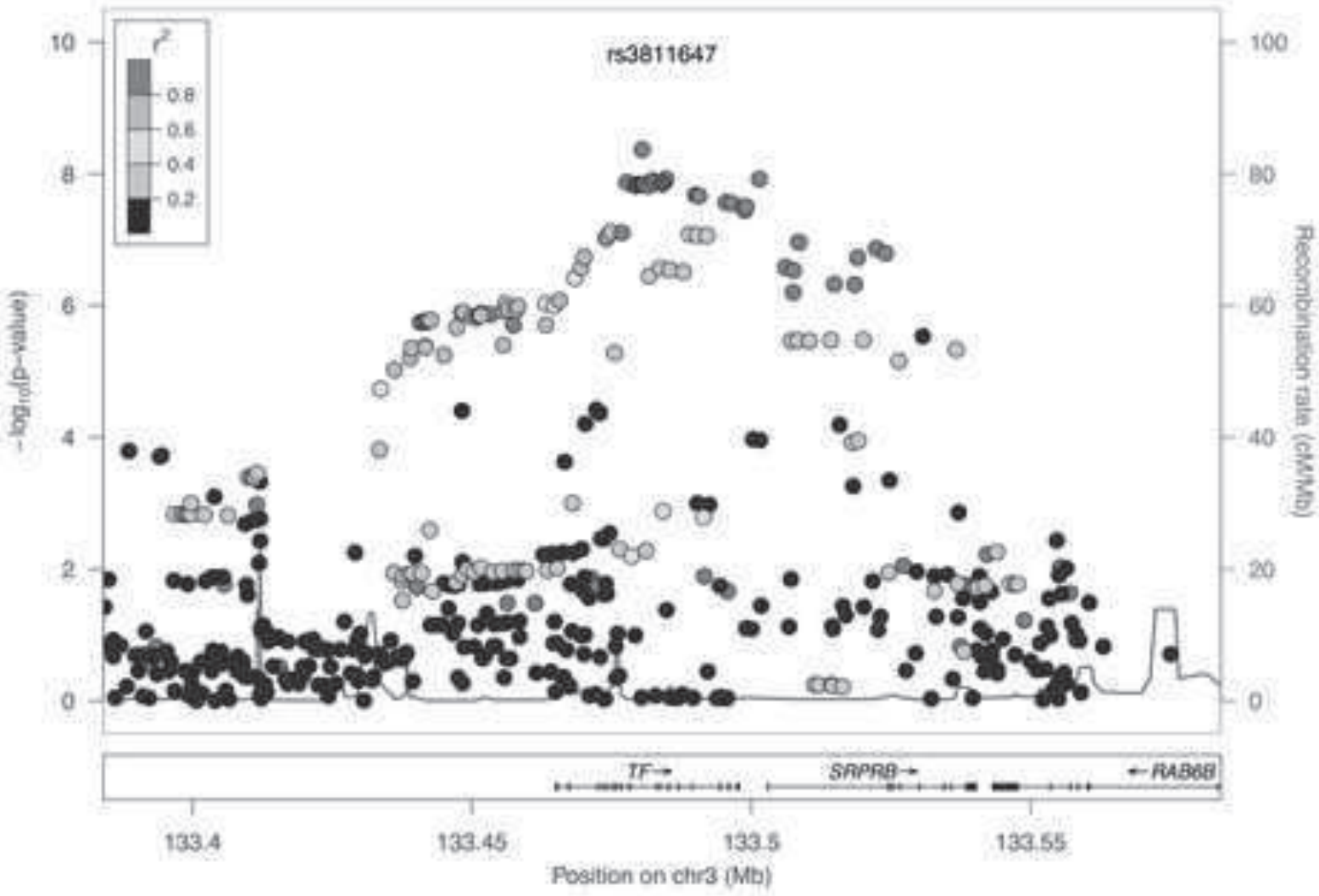

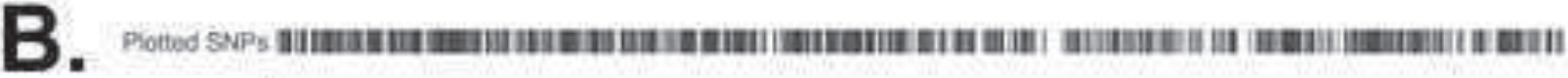

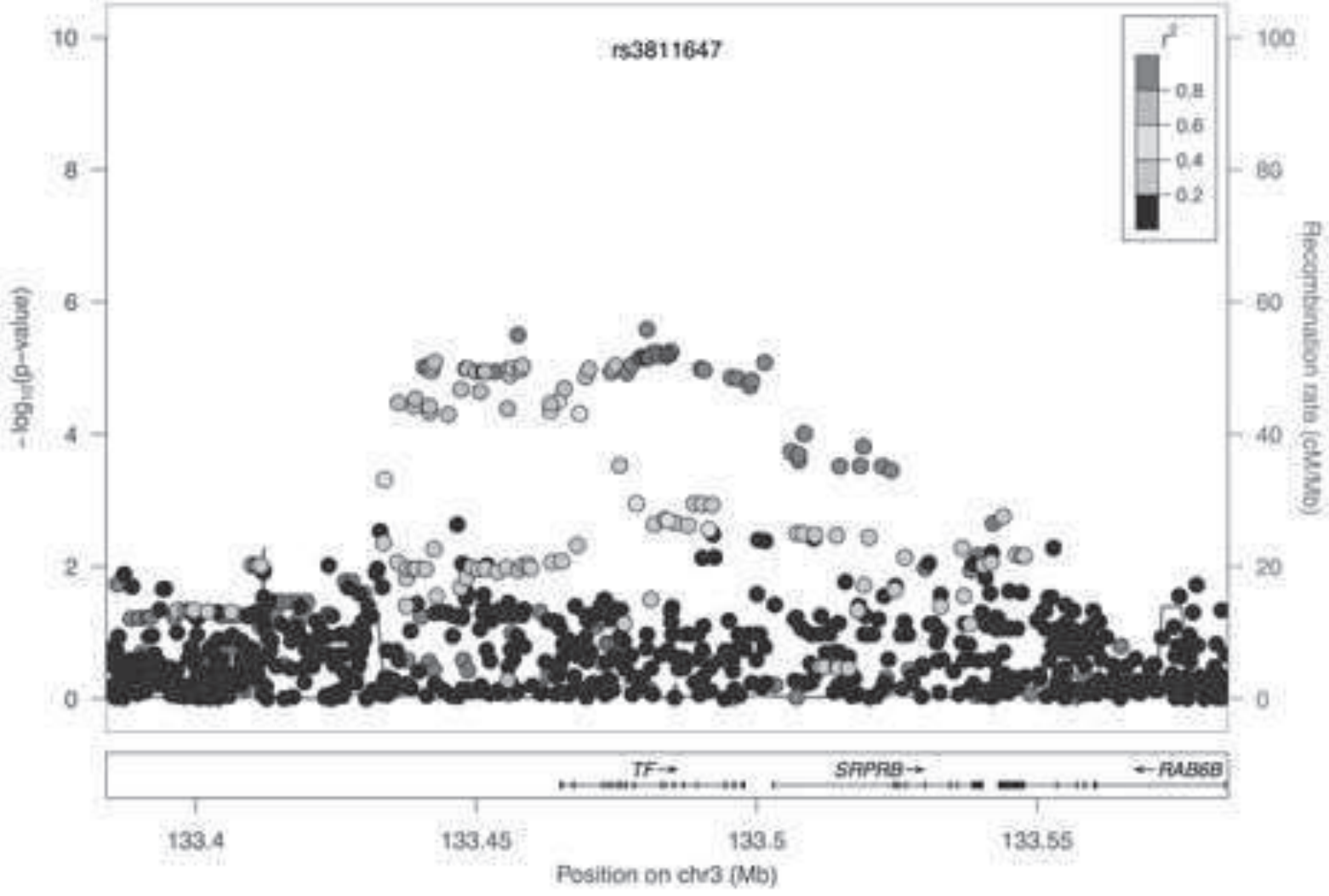




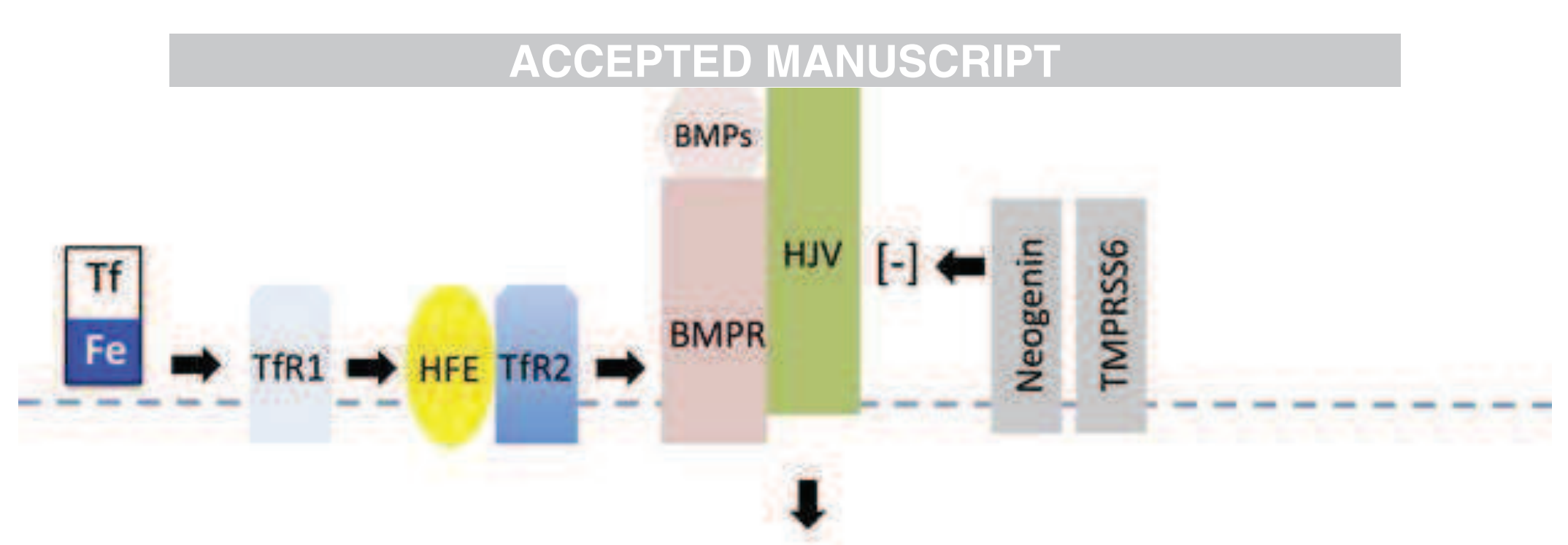

SMAD 1/5/8

HEPCIDIN

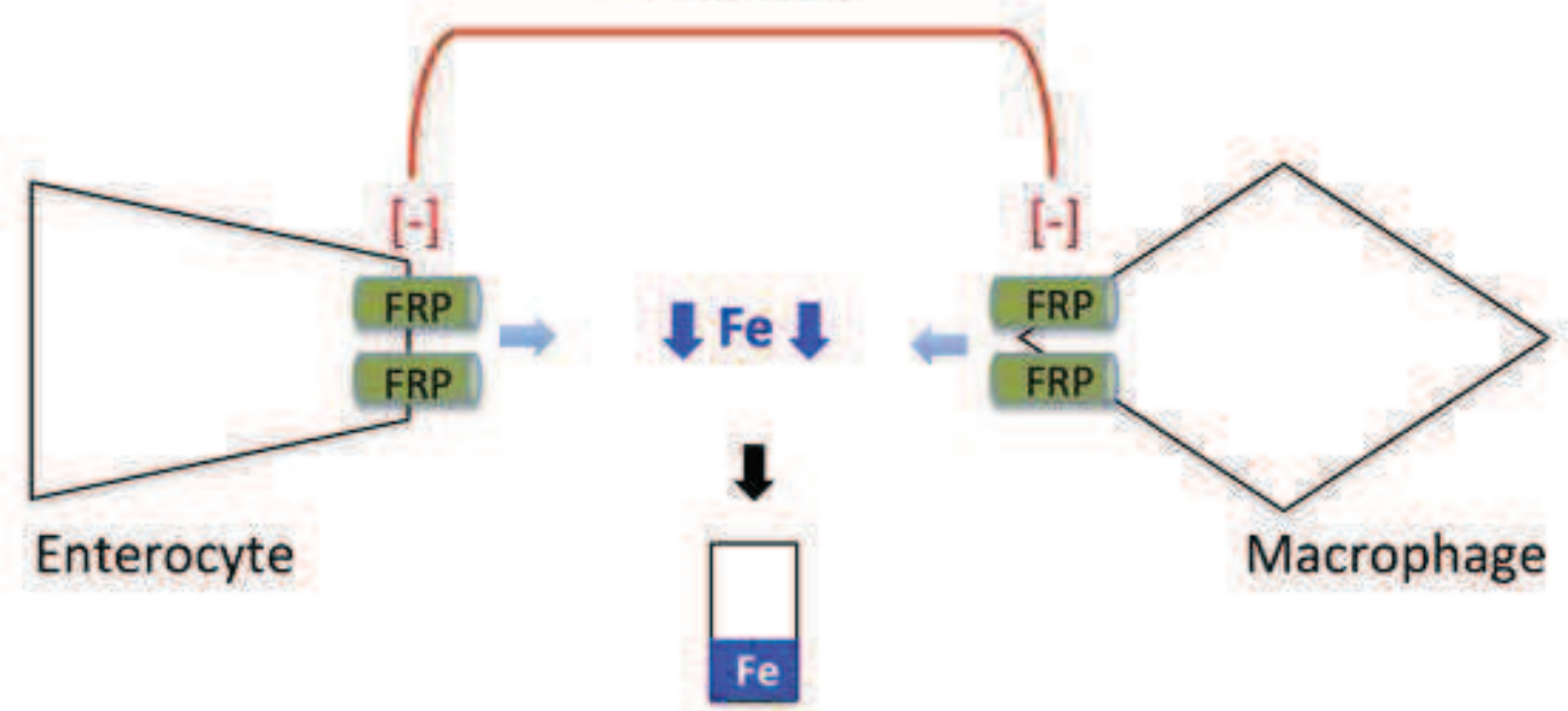

